\title{
PENGEMBANGAN APLIKASI MANAJEMEN INFORMASI MAGANG TEROWONGAN ANGIN KECEPATAN RENDAH INDONESIA
}

\author{
Ivransa Zuhdi Pane \\ Program Studi Informatika, Universitas Multimedia Nusantara \\ ivransa.zuhdi@lecturer.umn.ac.id
}

Submitted February 2, 2020; Revised March 20, 2020; Accepted March 24, 2020

\begin{abstract}
Abstrak
Aplikasi manajemen informasi magang di fasilitas Terowongan Angin Kecepatan Rendah Indonesia bermanfaat dalam mendukung tugas manajemen pengelola yang terkait dengan kegiatan magang, mulai dari registrasi, alokasi tugas, pemantauan pelaksanaan tugas hingga evaluasi hasil kerja peserta magang. Aplikasi ini diharapkan tidak hanya mendukung produktivitas dan kinerja, namun juga memberi masukan kepada manajemen pengelola dalam mengambil keputusan yang terkait dengan pendayagunaan peserta magang agar terwujud sinergi yang berdampak positif pada kelancaran proses bisnis layanan pengujian terowongan angin secara keseluruhan. Untuk merealisasikannya, maka suatu kegiatan rekayasa piranti lunak dengan metodologi prototyping dilaksanakan untuk membangun aplikasi, yang selanjutnya dioperasikan pada platform desktop dan berfungsi sesuai kebutuhan.
\end{abstract}

Kata Kunci : uji terowongan angin, piranti lunak

An internship information management application at Indonesian Low Speed Wind Tunnel facility is useful for supporting managerial tasks related to internship activities, ranging from registration, task allocation, task implementation supervision to evaluation of the work results of the apprentices. This application is expected to not only support productivity and performance, but also provide input for management in making decisions related to the employment of apprentices in order to realize a synergy that has a positive impact on the smooth process of the wind tunnel test service business as a whole. To realize it, a software engineering activity by adopting prototyping methodology is carried out to build the application to be then operated in a desktop platform and be used as needed.

Keywords : wind tunnel test, software

\section{PENDAHULUAN}

Terowongan Angin Kecepatan Rendah Indonesia (TAKRI) merupakan fasilitas uji terowongan angin yang terletak di Kawasan PUSPIPTEK, Tangerang Selatan, dan dikelola oleh Badan Pengkajian dan Penerapan Teknologi (BPPT), dimana akses penggunaannya bersifat terbuka baik terhadap pengguna jasa uji terowongan angin maupun mahasisa / pelajar yang ingin melaksanakan kegiatan magang [1]. Beberapa tahun belakangan ini, jumlah peserta magang di TAKRI mengalami peningkatan dan hal ini berimbas pada pengelolaan data yang terkait dengan kegiatan magang ini, dimana muncul tuntutan akan adanya suatu sarana berbasis teknologi informasi dalam bentuk piranti lunak aplikasi yang dapat mengefektifkan serta mengefisienkan manajemen informasi magang dengan cara terotomatisasi dan tidak lagi menggunakan cara manual tradisional, seperti yang selama ini masih diterapkan. Dengan adanya aplikasi manajemen informasi magang ini, maka kegiatan registrasi, alokasi tugas, pemantauan pelaksanaan tugas hingga evaluasi hasil kerja dari para peserta magang dapat dilakukan secara terpadu dan terkendali, yang pada gilirannya dapat mendorong produktivitas dan kinerja pihak manajemen TAKRI dalam mengelola kegiatan magang secara keseluruhan dan tersinergikan dengan proses bisnis TAKRI. Latar belakang inilah yang memotivasi dilaksanakannya kegiatan penelitian ini, 
dengan tujuan untuk mewujudkan aplikasi yang dimaksud tersebut melalui kegiatan rekayasa piranti lunak, yang dimulai dari tahap analsis kebutuhan sampai dengan implementasi. Bagian berikutnya dari makalah ini membahas metodologi yang digunakan untuk membangun aplikasi target, disusul dengan uraian tentang hasil kegiatan rekayasa, dan diakhiri dengan simpulan.

\section{METODE PENELITIAN}

Metode penelitian yang digunakan untuk membangun aplikasi manajemen informasi magang TAKRI adalah prototyping. Seperti diilustrasikan dalam Gambar 1, prototyping merupakan rangkaian kegiatan rekayasa piranti lunak yang dicirikan dengan adanya konstruksi prototipe (purwarupa) untuk mempermudah penggalian kebutuhan piranti lunak khususnya di sisi kustomer, dan terdiri dari tahap analisis kebutuhan, tahap perancangan, tahap konstruksi prototipe, dan tahap evaluasi umpan balik [2]. Tahapan kegiatan ini dilaksanakan secara bersiklus dalam kurun waktu singkat, dimana hasil konstruksi dalam suatu siklus kelak digunakan di siklus berikutnya secara teriterasi untuk menambah atau menyempurnakan fitur-fitur yang diinginkan sesuai kebutuhan kustomer.

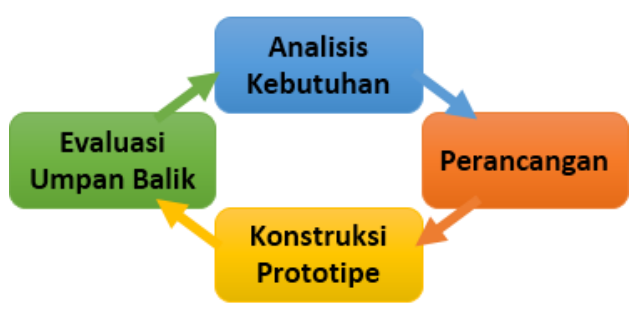

\section{Gambar 1. Konsep Prototyping}

Tahap analisis kebutuhan merupakan tahap awal dimana kebutuhan piranti lunak digali dan divalidasi melalui wawancara dengan pengguna potensial, observasi dan studi literatur. Hasil tahap analisis kebutuhan selanjutnya digunakan dalam tahap perancangan, untuk menyusun rancangan basis data, antarmuka pengguna dan algoritma. Setelah itu, dilakukanlah konstruksi kode aplikasi (awalnya masih bersifat prototipe dan selanjutnya secara bertahap menjadi aplikasi target) yang disertai juga dengan uji dan validasi terhadap kompilasi kode aplikasi tersebut guna memastikan operabilitas aplikasi. Hasil dari konstruksi ini kemudian diujicobakan ke pengguna, yang selanjutnya dimintai pendapat / saran terkait dengan aspek penggunaan aplikasi dan aspek terkait lainnya. Masukan dari pengguna ini dijadikan bahan untuk dikaji pada tahap analisis di siklus prototyping berikutnya.

\section{HASIL DAN PEMBAHASAN}

Kegiatan analisis kebutuhan dilaksanakan melalui wawancara terhadap pengguna dari pihak manajemen TAKRI, observasi terhadap mekanisme pengelolaan kegiatan magang yang selama ini berlangsung, dan studi literatur, khususnya terhadap aturan internal yang mengatur kegiatan magang di TAKRI. Hasil dari kegiatan ini ditunjukkan dalam use case diagram dan activity diagram pada Gambar 2 hingga Gambar 6 [3].

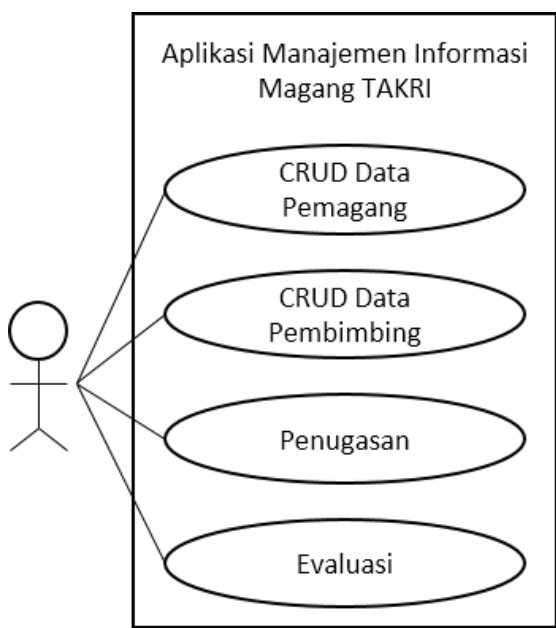

Gambar 2. Use Case Diagram Aplikasi Manajemen Informasi Magang TAKRI 


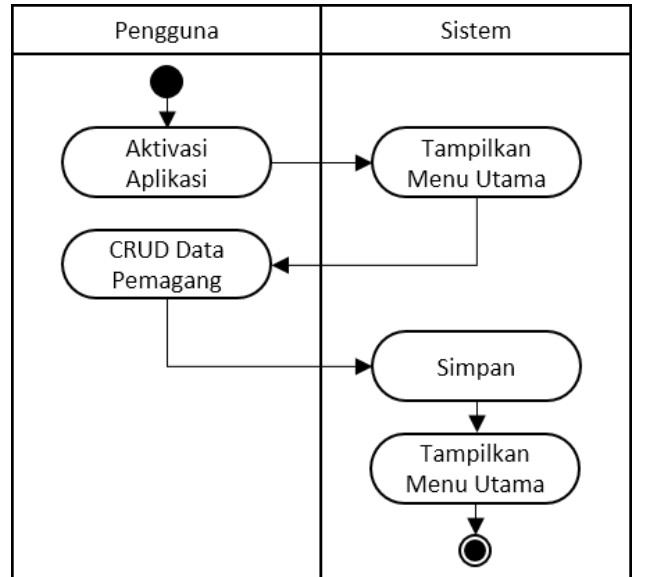

Gambar 3. Activity Diagram CRUD Data Pemagang

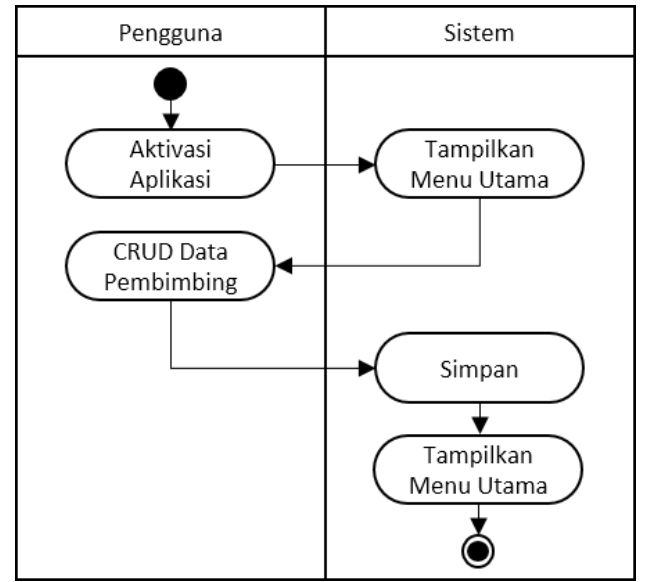

Gambar 4. Activity Diagram CRUD Data Pembimbing

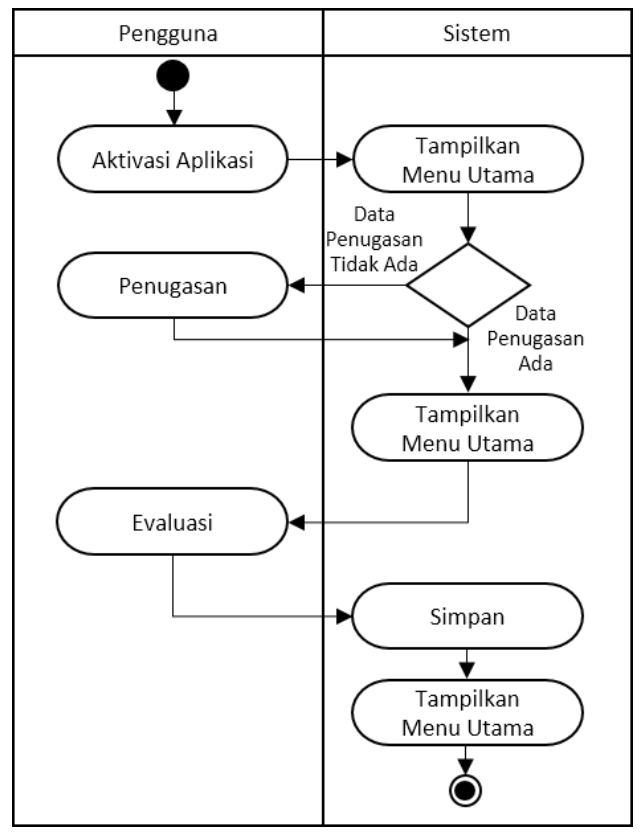

Gambar 5. Activity Diagram Evaluasi

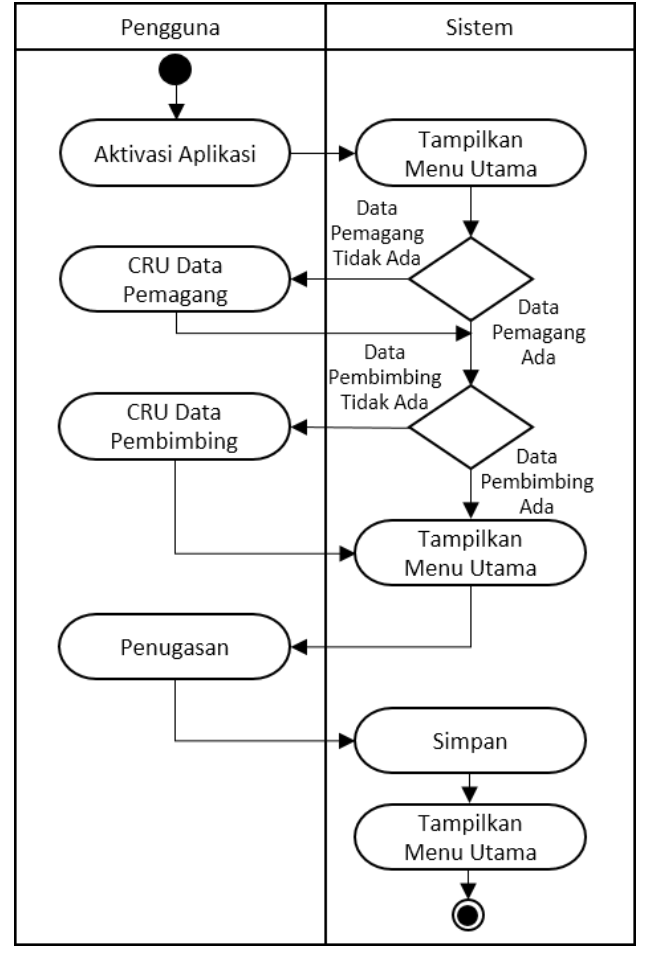

Gambar 6. Activity Diagram Penugasan

Kegiatan perancangan dilakukan untuk menyusun rancangan antarmuka pengguna, basis data, dan algoritma/skenario penggunaan aplikasi. Rancangan antarmuka ditunjukkan dalam Gambar 7 hingga Gambar 10, yang masing-masing memuat antarmuka create, read, update \& delete (CRUD) data pemagang (dalam hal ini bertindak juga sebagai menu utama), CRUD data pembimbing, penugasan, dan evaluasi [4]. Sedangkan tabel-tabel dari basis data ditunjukkan dalam Tabel 1 hingga Tabel 3, masing-masing memuat tabel pemagang, tabel pembimbing, dan tabel penugasan [5].

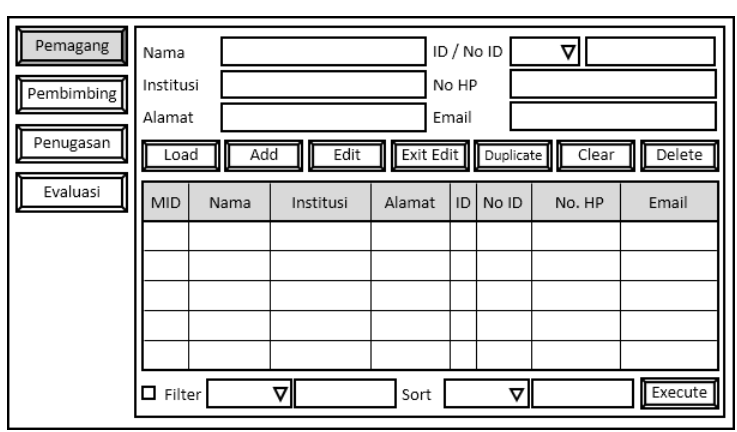

Gambar 7. Rancangan Antarmuka CRUD Data Pemagang 


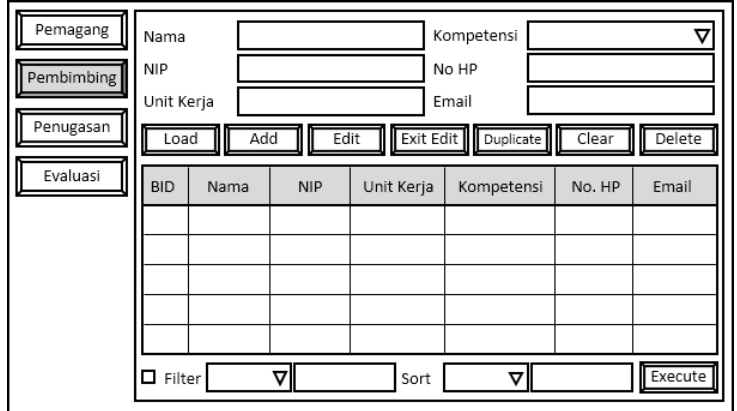

Gambar 8. Rancangan Antarmuka CRUD Data Pembimbing

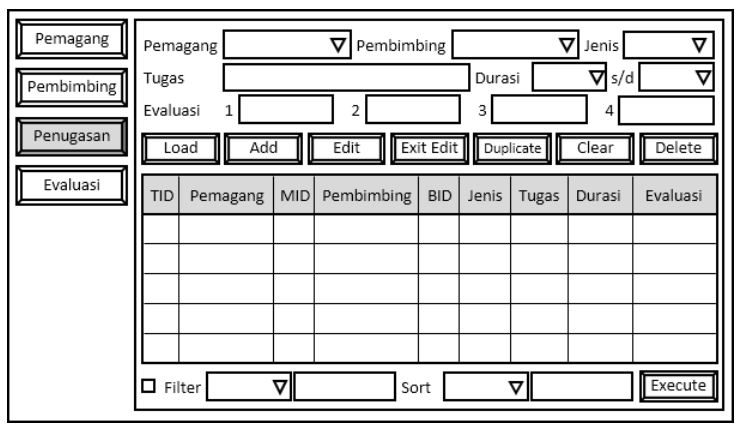

Gambar 9. Rancangan Antarmuka Penugasan

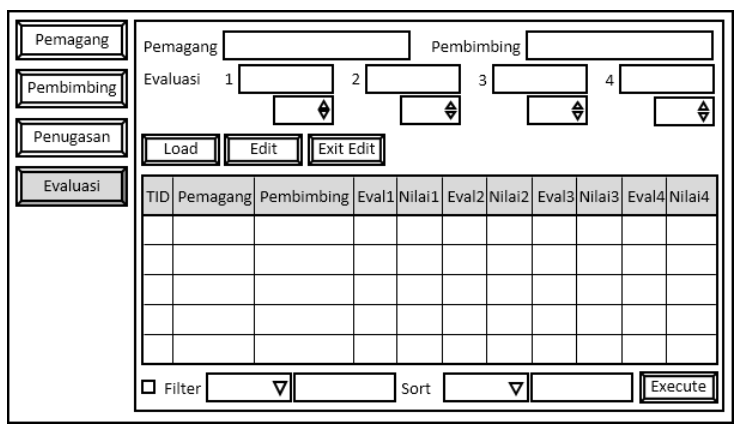

Gambar 10. Rancangan Antarmuka Evaluasi

Tabel 1. Basis Data - Tabel Pemagang

\begin{tabular}{|c|c|c|c|}
\hline No & NamaField & Jenis & Keterangan \\
\hline 1 & MID & Integer & Primary, AutoIncrement \\
\hline 2 & Nama & VarChar & Unique \\
\hline 3 & Institusi & VarChar & \\
\hline 4 & Alamat & VarChar & \\
\hline 5 & ID & VarChar & \\
\hline 6 & ID_No & VarChar & \\
\hline 7 & NoHP & VarChar & \\
\hline 8 & Email & VarChar & \\
\hline
\end{tabular}

Tabel 2. Basis Data - Tabel Pembimbing

\begin{tabular}{|c|c|c|c|}
\hline No & NamaField & Jenis & Keterangan \\
\hline 1 & BID & Integer & Primary, AutoIncrement \\
\hline 2 & Nama & VarChar & Unique \\
\hline 3 & NIP & Integer & Unique \\
\hline
\end{tabular}

\begin{tabular}{|c|c|c|l|}
\hline 4 & UnitKerja & VarChar & \\
\hline 5 & Kompetensi & VarChar & \\
\hline 6 & NoHP & VarChar & \\
\hline 7 & Email & VarChar & \\
\hline
\end{tabular}

Tabel 3. Basis Data - Tabel Penugasan

\begin{tabular}{|c|c|c|c|}
\hline No & NamaField & Jenis & Keterangan \\
\hline 1 & TID & Integer & Primary, AutoIncrement \\
\hline 2 & MID & Integer & \\
\hline 3 & BID & Integer & \\
\hline 4 & Jenis & VarChar & \\
\hline 5 & Tugas & VarChar & \\
\hline 6 & DurasiAwal & Date & \\
\hline 7 & DurasiAkhir & Date & \\
\hline 8 & Evaluasi1 & VarChar & \\
\hline 9 & Evaluasi2 & VarChar & \\
\hline 10 & Evaluasi3 & VarChar & \\
\hline 11 & Evaluasi4 & VarChar & \\
\hline 12 & Nilai1 & Integer & \\
\hline 13 & Nilai2 & Integer & \\
\hline 14 & Nilai3 & Integer & \\
\hline 15 & Nilai4 & Integer & \multicolumn{1}{|l|}{} \\
\hline
\end{tabular}

Skenario umum penggunaan aplikasi dapat diuraikan sebagai berikut:

1. Pengguna melakukan aktivasi aplikasi dan sistem akan menampilkan menu Pemagang sebagai menu utama;

2. Pengguna memasukkan data nama hingga email pemagang, lalu menekan button Add untuk menyimpan data;

3. Pengguna beralih ke menu Pembimbing dengan menekan button Pembimbing, memasukkan data nama hingga email pembimbing, lalu menekan button Add untuk menyimpan data;

4. Pengguna beralih ke menu Penugasan dengan menekan button Penugasan, memilih Pemagang dan Pembimbing, lalu memasukkan data lainnya (jenis tugas hingga empat butir evaluasi) dan kemudian menekan button Add untuk menyimpan data;

5. Pengguna beralih ke menu Evaluasi dengan menekan button Evaluasi, memilih Pemagang dari grid di bagian bawah, menekan button Edit, memasukkan empat nilai evaluasi sesuai butir evaluasi, dan menekan kembali button Edit untuk menyimpan data. 


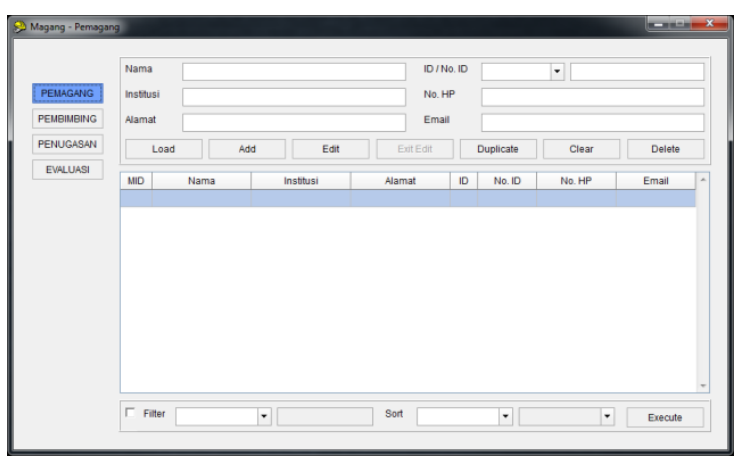

Gambar 11. Antarmuka Aktual Menu Pemagang

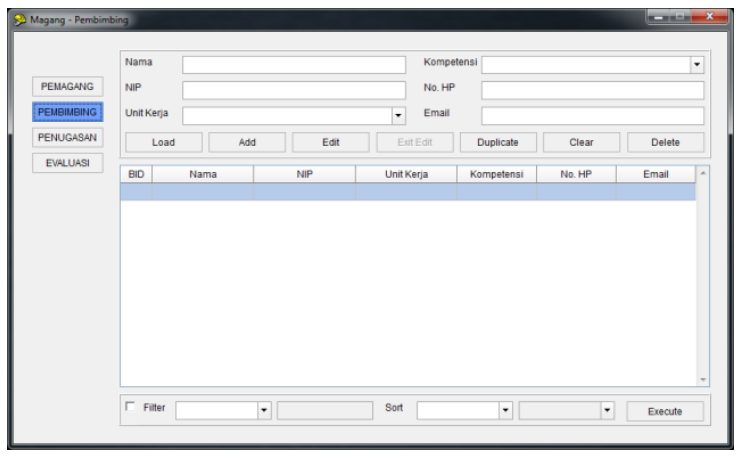

Gambar 12. Antarmuka Aktual Menu Pembimbing

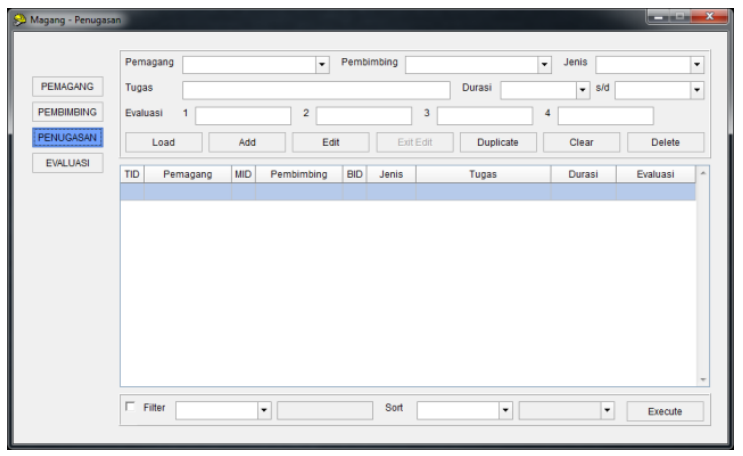

Gambar 13. Antarmuka Aktual Menu Penugasan

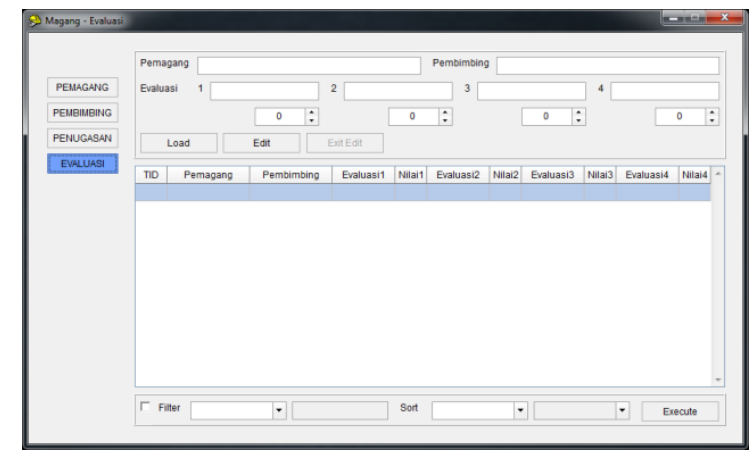

Gambar 14. Antarmuka Aktual Menu Evaluasi
Konstruksi aplikasi manajemen informasi magang TAKRI dilakukan dengan merujuk kepada hasil perancangan sebelumnya dan menggunakan bahasa pemrograman Object Pascal [6]. Sedangkan untuk pengelolaan basis data, digunakan server basis data MySQL [7]. Hasil kegiatan ini ditunjukkan dalam Gambar 11 hingga 14. Gambar 11 menunjukkan antarmuka menu pemagang, yang memungkinkan pengguna melakukan CRUD terhadap data pemagang yang akan mengikuti kegiatan magang di TAKRI, seperti nama, alamat dan atribut identitas. Gambar 12 menunjukkan antarmuka menu pembimbing, yang memungkinkan pengguna melakukan CRUD terhadap data pembimbing yang diproyeksikan akan membimbing pemagang, seperti nama, unit kerja dan kompetensi. Gambar 13 menunjukkan antarmuka menu penugasan, yang memungkinkan pengguna melakukan CRUD terhadap data penugasan antara pembimbing dan pemagang, seperti jenis penugasan, uraian tugas dan kriteria evaluasi kinerja pemagang. Gambar 14 menunjukkan antarmuka menu evaluasi, yang memungkinkan pengguna melakukan CRUD terhadap data evaluasi kinerja pemagang berdasarkan kriteria yang didefinisikan dalam menu penugasan.

Pengujian dan validasi terhadap hasil konstruksi aplikasi dilakukan dengan menggunakan sejumlah kasus uji yang dikaji dan ditentukan untuk mampu memastikan operabilitas aplikasi, seperti :

- Melakukan transisi antar menu untuk memvalidasi apakah perilaku setiap menu telah sesuai dengan spesifikasi pada saat diaktivasi;

- Memasukkan data, baik yang valid maupun tidak valid, untuk memastikan apakah constraint yang diberlakukan sesuai dengan spesifikasi terpenuhi atau tidak;

- Menguji ketergantungan satu menu terhadap menu lainnya, seperti menu Evaluasi terhadap menu Penugasan, 
dimana menu Evaluasi tidak akan berfungsi sebelum adanya penugasan yang didefinisikandi menu Penugasan.

\section{Tabel 4. Hasil Utama Uji Aplikasi}

\begin{tabular}{|c|c|c|}
\hline No & Uraian Uji & Hasil \\
\hline 1 & Aktivasi menu utama (menu pemagang) & Sukses \\
\hline 2 & $\begin{array}{l}\text { Transisi antar menu : } \\
\text { a. Pemagang } \leftrightarrow \text { Pembimbing } \\
\text { b. Pemagang } \leftrightarrow \text { Penugasan } \\
\text { c. Pemagang } \leftrightarrow \text { Evaluasi } \\
\text { d. Pembimbing } \leftrightarrow \text { Penugasan } \\
\text { e. Pembimbing } \leftrightarrow \text { Evaluasi } \\
\text { f. Penugasan } \leftrightarrow \text { Evaluasi } \\
\end{array}$ & $\begin{array}{l}\text { Sukses } \\
\text { Sukses } \\
\text { Sukses } \\
\text { Sukses } \\
\text { Sukses } \\
\text { Sukses }\end{array}$ \\
\hline 3 & $\begin{array}{l}\text { CRUD menu Pemagang: } \\
\text { a. Input/edit data valid } \\
\text { b. Pesan error input/edit data invalid : } \\
\text { - Panjang data melebihi batas definisi } \\
\text { - Penulisan No ID tidak formal } \\
\text { - Penulisan email tidak formal }\end{array}$ & $\begin{array}{l}\text { Sukses } \\
\text { Sukses } \\
\text { Sukses } \\
\text { Sukses }\end{array}$ \\
\hline 4 & $\begin{array}{l}\text { CRUD menu Pembimbing: } \\
\text { a. Input/edit data valid } \\
\text { b. Pesan error input/edit data invalid : } \\
\text { - Panjang data melebihi batas definisi } \\
\text { - Penulisan NIP tidak formal } \\
\text { - Penulisan email tidak formal }\end{array}$ & $\begin{array}{l}\text { Sukses } \\
\text { Sukses } \\
\text { Sukses } \\
\text { Sukses }\end{array}$ \\
\hline 5 & $\begin{array}{l}\text { CRUD menu Penugasan: } \\
\text { a. Input/edit data valid } \\
\text { b. Pesan error input/edit data invalid : } \\
\quad \text { - Panjang data melebihi batas definisi }\end{array}$ & $\begin{array}{l}\text { Sukses } \\
\text { Sukses }\end{array}$ \\
\hline 6 & $\begin{array}{l}\text { CRUD menu Evaluasi : } \\
\text { a. Input/edit data valid }\end{array}$ & Sukses \\
\hline 7 & $\begin{array}{l}\text { Dependensi antar menu : } \\
\text { a. Tidak ada data pemagang : } \\
\text { - Pesan warning menu Penugasan } \\
\text { - Pesan warning menu Evaluasi } \\
\text { b. Tidak ada data pembimbing: } \\
\text { - Pesan warning menu Penugasan } \\
\text { - Pesan warning menu Evaluasi } \\
\text { c. Tidak ada data penugasan : } \\
\text { - Pesan warning menu Evaluasi }\end{array}$ & $\begin{array}{l}\text { Sukses } \\
\text { Sukses } \\
\text { Sukses } \\
\text { Sukses } \\
\text { Sukses }\end{array}$ \\
\hline
\end{tabular}

Perbaikan yang timbul karena adanya defect ketika proses pengujian dan validasi dilakukan selanjutnya dilaksanakan dengan melokalisasi dan menghilangkan sumber defect, yang kemudian diteruskan dengan pengujian regresi untuk memastikan bahwa defect telah tertangani [8].

Kegiatan evaluasi umpan balik diawali dengan ujicoba prototipe aplikasi yang telah selesai dalam suatu siklus prototyping oleh pengguna potensial. Saran, ide dan pendapat dari pengguna ini, seandainya disepakati untuk diadopsi, akan dijadikan bahan untuk dianalisis pada siklus prototyping berikutnya [9]. Siklus prototying akan terus berlanjut dan dinyatakan berhenti apabila pengguna telah menganggap aplikasi telah memenuhi spesifikasi yang dibutuhkan dan aplikasi dinyatakan dapat digunakan untuk kondisi operasional.

\section{SIMPULAN}

Pengembangan aplikasi manajemen informasi magang TAKRI telah dilaksanakan melalui serangkaian siklus prototyping guna membangun aplikasi yang mampu mendukung aktivitas manajemen TAKRI dalam mengelola kegiatan magang secara terkendali dan terpadu. Penggunaan aplikasi ini diharapkan juga dapat memberi masukan kepada pihak manajemen TAKRI dalam bentuk dukungan pengambilan keputusan yang didasarkan pada hasil evaluasi pemagang, seperti perekrutan pemagang menjadi pegawai apabila hasil evaluasi pemagang bernilai baik. Pengembangan lanjutan dari aplikasi ini juga sangat disarankan mengingat dinamika proses bisnis TAKRI yang sedikit banyaknya berimbas pada mekanisme pengelolaan magang di masa mendatang.

\section{DAFTAR PUSTAKA}

[1] "Indonesian Low Speed Tunnel." [Online]. Available: http://bbta3.bppt.go.id/fasilitas.

[Accessed: 01-Feb-2020].

[2] R. Pressman and B. Maxim, Software Engineering A Practitioner's Approach, 8th ed. McGraw-Hill, 2014.

[3] B. Rumpe, Modeling with UML. Springer, 2016.

[4] B. Shneiderman and C. Plaisant, Designing The User Interface, 5th ed. Pearson, 2009.

[5] T. Connolly and C. Begg, Database Systems. Pearson, 2014. 
[6] M. Abiola-Ellison, Getting Started With Lazarus and Free Pascal. Createspace Independent Pub, 2015.

[7] P. Dubois, MySQL Cookbook, 3rd ed. O’Reilly Media, 2014.
[8] B. Hendradjaya, Konsep Dasar Pengujian Perangkat Lunak. ITB Press, 2017.

[9] A. Stellman and J. Greene, Applied Software Project Management. O’Reilly Media, 2005. 